\title{
NOVENAS Y RELIGIOSIDAD POPULAR EN LA INDEPENDENCIA DE COLOMBIA
}

\author{
Novena and popular religiosity during Colombian Independence
}

\author{
Carlos Arboleda Mora ${ }^{\mathrm{I}}$
}

\section{Resumen}

En una sociedad no secular como lo es la sociedad colonial colombiana del siglo XVIII, no hay distinción entre religión y política. Una de las formas de comprobar esto es los análisis de los símbolos, los ritos y la religiosidad popular usados en la época; y en este caso, de los textos novenarios y de sermones. El método seguido es el análisis de los textos de cronistas de la época, de las novenas, los sermones y los catecismos de tipo político. Se puede ver en el contenido de estos documentos cómo tanto centralistas como federalistas y patriotas como realistas tratan de usar los medios religiosos para implorar la ayuda divina en el conflicto y para inculcar y legitimar sus ideas políticas en la población. Especialmente hay novenas, sermones y catecismos de tinte patriota unos y de orientación realista otros. Era el mismo Dios el que tenía que atender las súplicas de ayuda y justificar la filosofía de ambos bandos. Se ve claramente el uso político de los símbolos religiosos que tienen un gran poder sobre la población.

Palabras clave: Religiosidad popular; Religión y política; Independencia de Colombia; Novenas; Catecismos políticos.

\section{Abstract}

In a non-secular society like that of Colombia during the colonial period of the 18 th-century, there was no distinction between religion and politics. This can be evidenced in the analysis of the symbols, rites, and popular religiosity of the time, in this specific case: novenas and sermons. Thus, the article studies the works of chroniclers, novenas, sermons, and political catechisms of the time. Such analysis reveals that both centralists

1 Doctor en Filosofía. Profesor de la Universidad Pontificia Bolivariana, Colombia.

Correo electrónico: carlos.arboleda@upb.edu.co 
and federalists, patriots and royalists tried to use religious means to ask for divine intervention in the conflict, and to teach and legitimate their political views. Particularly, there are novenas, sermons, and catechisms with both patriot and royalist orientation. It was God who had to respond to the pleas and justify the philosophy of both positions. It is concluded that the political use of religious symbols has a significant influence in the people.

Keywords: Popular Religiosity; Religion and Politics; Colombian Independence; Novena; Political Catechism.

\section{Introducción}

El tema de la relación entre religión y política en la independencia ha sido muy estudiado en los últimos años después de un tiempo en el que la categoría religión se había expulsado de las ciencias sociales. Desde los años 90 del siglo XX hay un renacimiento de estos estudios como lo muestran Cortés (1996), GRCS (2001) y Arboleda (2017). Fuentes para el estudio de la religiosidad popular las encontramos en cronistas de la época como José María Caballero, José Manuel Restrepo, José Manuel Groot, y algunas documentaciones como textos de novenas, discursos, sermones, catecismos etc. También se tienen los libros devocionarios y libros de espiritualidad o de costumbres muy propios del siglo XIX. Ya en el siglo XX, van apareciendo estudios con mayor o menor rigor científico según el autor como los de Roberto María Tisnés, Ana María Bidegaín, Javier Ocampo López, William Elvis Plata, Hermes Tovar Pinzón, Fernán González, Helwar Hernando Figueroa, María Mercedes Arango, Pablo Moreno, José David Cortés, Jaime de Almeida y muchos otros como los que menciona Pita (2017). El objetivo de este trabajo es mostrar cómo se usaron los símbolos y ritos religiosos para defender posiciones realistas o patriotas en la época de la independencia colombiana y de manera especial se toman las novenas piadosas usadas para inculcar o fundamentar una u otra posición política.

\section{Metodología}

La metodología utilizada es de tipo historiográfico. Se ha tratado de rastrear fuentes primarias de novenas y de textos de la época independentista y textos secundarios de autores del siglo XIX e historiadores del $\mathrm{XX}$. Se han privilegiado los textos novenarios porque se percibe en ellos una importancia testimonial de primer orden ya que por su formato didáctico, religioso y popular, son una fuente inmejorable para el estudio de la Historia de las mentalidades. Con esos textos se hizo un análisis de sus contenidos bajo el criterio de favorabilidad o menos a la gesta emancipadora o a la corona española.

\section{Resultados}

En una sociedad no secular como la colonial, todos se consideraban católicos. En este periodo de dominio hispánico en la Nueva Granada fue notoria la influencia de la Iglesia a través de su mundo simbólico representado en las misas, devociones, festividades y demás expresiones. 
El periodo de Independencia que inicia en 1808 en el mundo hispanoamericano traería consigo una alta polarización política que de alguna forma tuvo su impacto en la sociedad y en la feligresía. Tan católicos eran los que defendían la potestad del rey de España, como los que luchaban por la independencia de la patria. De ahí, que todos orasen al mismo Dios por distintas causas. Los fieles adherían a una u otra causa, y lo mismo hacían sacerdotes y obispos. Ya el 23 de julio de $1810^{2}$, a las ocho de la mańana se publicó en la ciudad de Santa Fe un bando en el que se afirmaba que se mantenía en su integridad la fe católica y los derechos del rey Fernando VII (Caballero, 1902, p. 124). Pero en las luchas entre los mismos patriotas se nota el uso del símbolo religioso. El año de 1813 es una buena muestra de la unión fe y política, aún dentro de los mismos patriotas diferenciados entre centralistas y federalistas. En este año se adopta a Jesús Nazareno como Generalísimo de las tropas y el Dulcísimo Nombre de Jesús era el distintivo de ellas, se portaba como escarapela en los sombreros "pues todo hombre y mujer se distinguió con esta divina e incomparable divisa, á quien los ángeles humildes se postran y los demonios tiemblan" (p. 155).

Este distintivo del dulcísimo Nombre de Jesús lo dió el padre Botero de San Diego, según dice José María Caballero, y lo puso él mismo a todos los cañones, "y dijo que confiáramos, que por virtud del Dulce nombre de Jesús seríamos libres" (Caballero, 1902. P. 155). Los símbolos religiosos animaban a centralistas y federalistas. La misma creencia religiosa servía para entender el ataque de Antonio Baraya como un castigo de Dios (p. 156) o ver la ayuda directa de la Virgen en la batalla del 9 de enero de 1813:

"Se dijo por varias personas de crédito, y por muchas bocas, que cuando estaba el fuego en lo más vigoroso, andaba una mujer por entre las tropas y a la parte que más caían las balas; y después dicha mujer, aunque se inquirió no pareció, lo que se tiene por verosímil que fue María Santísima Nuestra Señora, para ampararnos y favorecernos. (p. 158-159).

En 1814, continúan las mismas súplicas y novenas pidiendo y celebrando triunfos patriotas. Grande fue la fiesta el 9 de enero cuando se supo el triunfo en Palacé: pólvora, música, toros, procesión con el Dulce Nombre de Jesús, iluminación de la ciudad (p. 192-193). Y el 24 de enero cuando llegó la noticia oficial del triunfo, se repitió la fiesta. (p. 193-194). Todo el año de 1814 y parte de 1815 continúa en la misma tónica. Pero la confianza en las Novenas y en los rezos, comienza a flaquear en los últimos meses de 1815.

A 22 (noviembre) se han comenzado nuevas rogativas en San Agustin, San Francisco y Santo Domingo, por el triunfo de nuestras armas. Yo creo que novenas ya no alcanzan, lo que debe alcanzar es la enmienda de las costumbres y penitencias, como en Ninive, pues lo que reina es la ambición, la usurpación, los robos, la poca justicia, la intriga, el egoismo, la usura, la lujuria, la embriaguez y la anarquía. Con estas relevantes virtudes no hay duda que progresará la República" (p. 227).

"Por cierto que la tal República se compondrá, como ahora llueven pepinos. Si ésto no se compone sino de picardías y maldades. Aunque más novenas se hagan, aunque los hombres buenos y mujeres virtuosas se cansen en pedir á Dios para que nos libre de calamidades y males que nos amenazan, no hay tusa, siempre seremos despojos del enemigo. Santo Dios. Tiemblo al imaginarlo"(p. 233).

2 Hay que tener en cuenta que en Colombia de Julio de 1810 a 1816 se da un período que algunos denominan Patria Boba que se distingue por el enfrentamiento entre federalistas y centralistas. Luego en 1816 comienza la reconquista española con Pablo Morillo que usa la represión contra los patriotas, período que termina en 1819 cuando empieza la república. 
Conocidas las malas noticias de la pérdida del Socorro, Puente Real y Chiquinquirá, la derrota de Rovira y las amenazas sobre la capital, vuelven a hacerse las novenas como última esperanza:

"Se han comenzado novenas á Nuestra Señora del Topo, en la Catedral; á Nuestro Amo, en Santo Domingo; en la Concepción, al Espiritu Santo; y a San Miguel y á Nuestra Señora del Descendimiento, y á Nuestro Amo, en San Francisco, y en todas las demás iglesias y conventos a diferentes santos, que es lo que realmente nos puede librar de esta terrible calamidad. Dios haga su voluntad y lo que mejor a cuenta nos esté"(p. 235).

El anhelo de patriotas y realistas de poseer la ayuda de Nuestra señora de Chiquinquirá es idéntico. Para poseer esa ayuda, hay que poseer también la imagen, tener el ícono es tener el poder. Manuel Serviez al ver acercarse la tropa realista a Chiquinquirá, toma la imagen y comienza a andar con ella. Portar la imagen es portar su fuerza, el ícono religioso mueve los sentimientos nacionales (p. 245-246). Cuando los españoles recuperan la imagen, le hacen una fastuosa entrada a la ciudad: se formaron 800 hombres de tropa, todas las religiones estuvieron presentes, se llevaron a la procesión los prisioneros de guerra, se cantaron las letanías y se colocó la imagen en un trono (p. 247-248). El mismo Pablo Morillo participaba en las festividades como antes lo hacían Antonio Nariño o el Presidente interino. En los días siguientes se hizo una misión y la novena a Nuestra Señora tal como lo narra Groot $(1953,479)$, además de ordenar la celebración anual de una fiesta denominada del "rescate" para hacer memoria de la recuperación de la imagen que estaba en manos de los patriotas. (AGOP, Sección XIII)

No es extraño que en la historia de estos países, las imágenes religiosas sean nombradas Generales o Generalas de los ejércitos. Nariño nombra a Jesús Nazareno "Generalísimo de los ejércitos" y se considera a la Virgen como protectora. Mucho más adelante, en la época de la violencia del siglo XX, se nombrará a la Virgen del Carmen patrona de los liberales y a la Virgen de Fátima patrona de los conservadores.

\section{Catecismos}

En esta época no sólo se crearon ritos patriotas y se usaron los recursos de la religiosidad popular para motivar el espíritu de independencia y libertad, sino que también se recurrió a los catecismos políticos y a los sermones.

Los catecismos políticos eran una forma de enseñanza propia de la iglesia que fue utilizada como medio de publicidad para ideas políticas. En una sociedad sacralizada en la que el catecismo tiene autoridad dogmática y moral, utilizar el catecismo para fines políticos le daba carácter sacralizante y autoritativo. De ahí el uso del método catequético para inculcar ideas que sería difícil enseñar si no fuera por un método válido para gente iletrada. Monárquicos e independentistas los utilizaron con fines distintos: los primeros para preservar el absolutismo de origen divino; los segundos para difundir e implantar el nuevo modelo ilustrado y republicano.

Estos catecismos se pueden estudiar tanto desde los antecedentes filosóficos o ideológicos que los influenciaron como de los movimientos sociales que propiciaron con el correr de los ańos una nueva mentalidad colectiva en cuanto introducían conceptos como ciudadanía, patria, pueblo y soberanía. Lo primero es la línea de Javier Ocampo López (1988) y lo segundo, la de Rafael Sagredo Baeza (1996). 
Esos catecismos, especialmente los de orientación republicana, recogen ideas ilustradas, interpretaciones bíblicas, o reflexiones de la filosofía política hispana de raíz escolástica, como son las de los jesuitas Juan de Mariana y Francisco Suárez o el dominico Francisco de Vitoria. (Sáenz 2010, p. 7)

Los clérigos patriotas se apoyaron en los teólogos juristas del siglo XVI, para hacer la justificación teológica de la independencia. Estos rechazaban la teoría del derecho divino de los reyes y defendían que la colectividad es la titular del poder político. Ningún gobernante debe considerarse investido por la divinidad. Para Francisco Suárez el pueblo delega su soberanía a un soberano a través de un pacto que

[...] debe entenderse que se estableció a manera de un pacto por el cual el pueblo transfirió al príncipe el poder con la carga y la obligación de cuidar el Estado y gobernarlo, y el príncipe aceptó tanto el poder como la condición: por ese pacto quedó firme y estable la ley real, o sea, la ley acerca del poder real. Por consiguiente, los reyes reciben este poder no inmediatamente de Dios sino del pueblo." (Suárez, 1970, p. 19-20)

La comunidad tiene la capacidad de levantarse contra el monarca cuando incumpla su tarea gracias a que ella conserva un poder suficiente para rechazarlo. Así toda forma de autoridad es una institución humana. (p. 18) En el acto de fundación del estado por el pacto, el poder político que reside en la comunidad por naturaleza, se relega en el soberano. Los clérigos asumieron esa doctrina de que la legitimidad del gobernante deriva del pueblo que es quien lo inviste de autoridad para su desempeño. Francisco de Victoria había dicho, por su parte:

"Desde cualquier punto de vista del Derecho positivo y humano, no hay razón alguna para que esta potestad (poder o soberanía) resida o recaiga en una o en otra persona, sino que es necesario que la misma comunidad sea capaz y tenga la potestad (el poder soberano) para autogobernarse”. (Victoria, 1960, p. 298)

Esto fue lo que hizo don Juan Fernández de Sotomayor al escribir su Catecismo o Instrucción popular (1814) con el fin de instruír a las gentes sobre la bondad de la independencia. Este catecismo negaba los títulos de conquista de España sobre América y hacía una fuerte crítica a su obra en estos territorios. ${ }^{3}$

El padre Juan Fernández de Sotomayor (1777-1849), cartagenero, fue uno de los curas más revolucionarios de la época, declaró la independencia de Mompox el 6 de agosto de 1810, fue obispo de Cartagena en 1834. Se encontró con el hecho independentista y decidió justificarlo, recordando la dureza

3 Son muchos los catecismos elaborados en esa época como lo muestran los estudios de Rafael Sagredo Baeza. De la colonia a la república. Los catecismos políticos americanos 1811-1827. Madrid: Fundación MAPFRE- Ediciones Doce Calles, 2009. Y el artículo "Actores políticos en los catecismos patriotas y republicanos americanos 1810-1827. En Historia Mexicana, XLV: 3, 1996. Pp. 501-538. En Colombia hubo varios catecismos entre 1814 y 1872 (Juan Fernández de Sotomayor. Catecismo o instrucción popular. Cartagena: Imprenta del estado, 1814. José Grau. Catecismo político arreglado a la constitución de la república de Colombia del 30 de agosto de 1821, Bogotá: Lora, 1824. Miguel Lizarralde. Catecismo político arreglado de la constitución de la república de Colombia. Zipaquirá: manuscrito, 1825. Juan José Nieto. Derechos y deberes del hombre en sociedad. Cartagena: Eduardo Hernández, 1834. Justo Arosemena. Principios de moral política redactados en un catecismo y varios artículos sueltos. Bogotá: Imprenta de Cualla, 1849. Cerbeleón Pinzón. Catecismo republicano para instrucción popular. Bogotá: el Mosaico, 1865. Santiago Pérez. Manual del ciudadano. Bogotá: La Escuela Normal periódico oficial de instrucción pública, 1872). 
y crueldad de la conquista y negando los derechos de Espańa a realizarla. (Ocampo, 2010, p. 129; Tovar, 2007, p. 126)

Su catecismo, impreso en Cartagena de Indias en 1814, está en consonancia con las tesis políticas del Padre Francisco de Victoria. Fue prohibido y la Inquisición abrió un proceso en su contra. En este catecismo revolucionario refuta los derechos o títulos de España sobre América, se deslegitima la donación del papa Alejandro VI a los reyes. Se afirma que los derechos de libertad e independencia ya los tenían los indígenas, y por eso la conquista ha sido una opresión por medio de la violencia y la ignorancia. Los espańoles siempre han considerado a los americanos como hombres de otra especie, inferiores, nacidos para obedecer y ser mandados como si fuesen un rebaño de bestias. La resistencia a los españoles se fundamenta en la ley natural que obliga a conservar la vida, la libertad y la propiedad individual. Por tanto la guerra es justa y santa, acaso la más justa y santa que ha visto el mundo de muchos siglos acá. La propagación de la religión cristiana no es título justo de dependencia pues es injurioso para ella el hecho de que ha sido usada para subyugar estos pueblos. Los mismos predicadores del Evangelio eran tan codiciosos y hambrientos de riqueza como sus compañeros conquistadores. Jesucristo no ha querido que alguno sea forzado a abrazar la religión. Critica así mismo los medios violentos utilizados en la evangelización. Para muestra se pueden ver unos textos:

"P. ¿De quién dependía la América antes de la revolución de España? R. De sus Reyes. P. ¿Esta sumisión o dependencia tenía algún fundamento en justicia? R. Ninguno tuvo en su principio. P. ¿Qué títulos se han alegado para mantener esta dependencia? R. Tres: a saber, la donación del Papa, la Conquista y la propagación de la Religión Cristiana. P. ¿La Donación del Papa no ha sido un título legítimo? R. No, porque el Vicario de Jesu-Cristo no puede dar ni ceder lo que no ha sido jamás suyo, mucho menos en calidad de Papa o sucesor de San Pedro, que no tiene autoridad ni dominio temporal, y el imperio que le fue confiado al mismo San Pedro, y que ha pasado a sus legítimos sucesores ha sido puramente espiritual como se evidencia por las mismas palabras que contienen la plenitud del poder Apostólico.

P. Pues qué ¿̨nosotros somos vasallos de España? R. No, ni nunca lo hemos sido. P. ¿Y por qué los españoles vindican para sí este derecho? R. Porque siempre han considerado a los americanos como hombres de otra especie inferiores a ellos, nacidos para obedecer y ser mandados como si fuésemos un rebaño de bestias.

P. ¿¿Pero la conquista de América no ha tenido trescientos años de posesión quieta y tranquila? R. Bien podría decirse que esta posesión ha sido turbada por repetidas conmociones parciales, que desgraciadamente se han malogrado; pero aun cuando fuese, esto sirve de justificar más nuestra conducta actual. P. ¿Por qué? R. Porque trescientos años de cadenas, de oprobios, de insultos, de depredaciones, en una palabra, de todo género de padecimientos en silencio y paciencia no pueden servir de prescripción contra millones de hombres; y ellos no podía dejar de interesar, algún día, a la Providencia a nuestro favor, devolviéndonos el precioso derecho de existir libres de la tiranía, y brindándonos la oportunidad de sacudir tan pesada como ignominiosa coyunda. P. ¿Luego la guerra que sostenemos es una guerra justa? R. Sí, una guerra justa y santa, y acaso la más justa y santa que se ha visto en el mundo de muchos siglos acá" (Ocampo López, 1980, p. 459-469)

Algunos planteamientos sobre los títulos legítimos aducidos por España para su dominio en América ya habían sido cuestionados desde el siglo XVI por teólogos españoles, entre ellos fray Antonio de Montesinos, 
fray Bartolomé de Las Casas y el padre Francisco de Vitoria en sus conocidas «Relecciones»: Del Estado, De los indios y Del derecho de guerra. Las tesis de Vitoria influyeron considerablemente en los criollos que defendieron y justificaron la independencia, y surgen del principio general de que los indios, antes de la llegada de los españoles, eran legítimos señores de sus cosas públicas y privadas. Vitoria rechazó la donación papal, la autoridad universal del emperador español y el derecho de hallazgo o descubrimiento, y otros.

Además, encontramos en el catecismo ideas relacionadas con la autoridad y la soberanía popular pues dada la invasión de España por Bonaparte, el pueblo americano reasume su soberanía anterior. El cura cartagenero defiende la independencia y considera que la guerra se justifica después de trescientos años de opresión, para tener el derecho a vivir libres de la tiranía.

Hubo también otros catecismos de corte republicano publicados ya en ańos posteriores a la independencia: el Catecismo político de José Grau, publicado en 1822 para el departamento del Orinoco, en la Gran Colombia; el Manual del colombiano de Tomás Lander, publicado en 1825; Máximas republicanas, publicado en Nueva York en 1827; el Catecismo del sentido común, escrito en Popayán en 1832; El catecismo republicano de Cerbeleón Pinzón y el Catecismo del verdadero republicano de Guillermo Michelena.(Ocampo López, 1997).

Los sermones, por su parte, también tenían su papel importante en la proclamación de ideas y justificaciones de los bandos enfrentados, así que se puede hablar de sermones realistas y sermones patrióticos. Generalmente, como dice Arce Escobar (2012a) después de analizar 29 sermones entre 1808 y 1821, los predicadores de los períodos 1808-1809 y 1816-1817 se mostraron leales al rey y a la teoría del origen divino de la autoridad. En cambio, los de los períodos 1810-1815 y después de 1819 apoyaron la república. (p. 277) La Biblia fue el apoyo principal para extraer los argumentos en favor de una u otra posición pues tenía la ventaja de ser un libro creído infalible, con autoridad absoluta pues era la palabra de Dios y el púlpito se consideraba el lugar donde hablaba el Espíritu Santo. Sus argumentos no se podían refutar y además, negarla significaba herejía, ostracismo, pecado, herejía, con todas las consecuencias sociales que ello acarreaba.

Los predicadores hacían interpretaciones, muchas veces abusivas, o aplicaciones amañadas para justificar su causa. Se daban casos extremos como considerar a la Nueva Granada el pueblo elegido por Dios y así Dios era el defensor de la República; o creer que Yavé en el Antiguo Testamento había fijado la monarquía como el mejor tipo de gobierno y que se le debía fidelidad absoluta al monarca. Se comparaba a España con la prostituta abandonada por Dios y castigada por medio de Napoleón (visión republicana) o a la Nueva Granada como la Jerusalén devastada vista por el profeta Isaías como consecuencia de haberse ido tras las ideas ilustradas (visión monárquica). ${ }^{4}$

Francisco de Paula Santander expidió un decreto el 26 de diciembre de 1819, ordenando a los curas predicar a sus fieles que defender el sistema republicano no era una herejía, que la independencia estaba

4 Para una visión amplia de este tipo de interpretaciones y aplicaciones de los textos bíblicos al contexto del conflicto independentista puede verse a José David Cortés Guerrero. "Los sermones en la Independencia colombiana. De la defensa del monarca espańol a la defensa de la república”, en Independencia. Historia diversa, ed. Bernardo Tovar Zambrano (Bogotá: Universidad Nacional de Colombia, 2012), 151-182. 
conforme con la religión cristiana y que sufrir otra Reconquista sería el peor de los males que se podría padecer. (Garrido, 2004, p. 462) Se buscaba contrarrestar el calificativo de "herejes" que se les aplicaba a los patriotas desde 1810. Se podía ser leal a la república y leal a Dios. Antes se predicaba que ser leal al rey era ser leal a Dios (dentro de la doctrina de la autoridad vicaria del monarca). Además, como dice Garrido, se salvaba la iglesia de caer junto con la monarquía. (Garrido, 2010)

Los sermones trataban de legitimar la independencia y así apuntalaban la república y la misma iglesia:

"Los contrarios no han ganado entre nosotros una acción en el campo de batalla; y aunque entraron en la capital de la Nueva Granada, y dominaron toda su comprensión y sus habitantes, fue porque nos hallábamos desunidos y por la justa indignación de Dios por nuestros pecados, valiéndose de ellos el señor como de un azote para castigarnos; así como se valió Antíoco en tiempos de Matatías para afligir a los judíos; y como en los días de San León Magno, se valió de Atila para castigar las culpas de los cristianos." (Arce Escobar, 2012b, p. 92)

Los sermones fueron utilizados como herramienta política con interpretaciones subjetivas o amañadas de la Biblia. Hay por cierto que entender el tiempo, el contexto, el cargo eclesiástico y aún el origen social de los predicadores para comprender su posición política. Por no ser parte del objetivo de este trabajo, no se hace análisis de algún texto sermonario pero se pueden consultar las referencias de varios de ellos en los trabajos de Arce Escobar (2012a y 2012b) y de Cortés Guerrero (2010b).

\section{Novenas realistas}

Además del uso de la novena para pedir el triunfo de las armas realistas o patrióticas, también hay las novenas con contenido realista o patriota.

En 1810, el doctor Mariano de Mendoza Bueno y Fontal publica una "Novena en culto del glorioso arcángel San Rafael”. Era este sacerdote de rica familia, párroco de Pore y Vicario de la provincia de los Llanos; un realista furibundo al punto de colocar al final de su novena una nota en que narra las cinco veces en que se ha visto al borde la muerte por haber resistido al juramento de independencia. Esta novena tuvo tres ediciones $(1810,1811,1816)$, en cuya nota final dice que anhela morir en la religión y obediencia en que vivieron y murieron sus padres.(Tisnés, 1971, p. 529-536) Nos dice R. Tisnés, que se valió de esta novena, y de otra publicada en 1811 llamada "Novena en honra del glorioso San Isidro, patrón de Madrid y especial protector de los pobres y labradores", para inculcar e insinuar sus ideas regalistas y tratar de masones y luteranos a los revolucionarios del 20 de julio de 1810 (p. 531). En la nota 4 de la novena habla de los filósofos masones que han difundido el veneno de la incredulidad, y pide oraciones por el obispo Juan Bautista Sacristán desterrado por los insurrectos:

"Pide el autor por el Ilmo. Sr. Don Juan Bautista Sacristán, legítimo prelado de la diócesis de Santafé, a quien los masones y nuevos luteranos del Nuevo Reino de Granda, han desterrado ocupándole todas sus rentas y haciendo que la grey quede sin pastor y el clero sin cabeza. Tal es el odio que tienen al sacerdocio de Nuestro Señor Jesucristo y el empeño de acabar con la religión”. (p. 531) 
Además, en la página 55 de la novena, compara esa filosofía masona a Luzbel que se rebeló contra Dios y que es lo que hacen los que pretenden derribar a los reyes del trono en que la mano del Altísimo los colocó.

"Esta misma filosofía es la que hoy ha enseñado a los espíritus fuertes que dominan y que a pretexto de una tiranía, aunque fantástica, que han hecho concebir en los reyes, pretenden derribarlos del trono en que los colocó la mano del Altísimo... así esta filosofía que llaman nueva los espíritus fuertes o débiles masones es tan rancia como el mismo diablo."

Así la novena está defendiendo el vicariato regio del rey y desprestigiando la ilustración denominándola masona y hereje.

El Dr. Mendoza Bueno publicó también en 1816 (en tiempos de la pacificación de Morillo) una Novena en honra del glorioso San Isidro patrón de Madrid y especial protector de los pobres y labradores, a quienes la dedica su autor", que ya había sido escrita en 1811. En esta, una nota final dice:

"Hoy día que por la bondad de Nuestro Dios nos vemos libres de los impíos y tiranos que nos afligían, y que por el valor de los generosos españoles han sido expulsos los que descaradamente atacaban el trono y el altar, debemos pensar y hablar de diverso modo".

"Qué pintura tan original del carácter de los falsos doctores, de los ciegos filósofos y de los infames masones que apestan nuestra América... Pidamos a Dios Nuestro Señor por la libertad del monarca español, a quien se concedieron estos dominios con la precisa obligación de establecer en ellos la religión católica y conservarla a toda costa" (Romero, 1960, 482)

Eran novenas que, a través de la devoción popular, infundían mantener la obediencia al rey de España y sostener el estado de cosas colonial.

\section{Novenas patriotas}

Por parte de los Patriotas, tenemos la novena del doctor Pablo Francisco Plata, rector del colegio San Bartolomé y cura de la catedral. Esta novena se titula "Novena en memoria y obsequio de los dolores de la Santísima Virgen María Nuestra Señora". (Con la licencia necesaria. Santafé. Imprenta del Estado por el C. J. M. Ríos: Año de 1816.-6º . Es una actualización de la novena a la situación de 1816 ya que el texto existía desde 1796. El doctor Plata era cura de la catedral de Bogotá en 1810, firmó la Constitución de la República en 1812, y la independencia de Cundinamarca en 1813.

Vale la pena transcribir su dedicatoria:

También sabéis, Señora, que los hombres no han sido hechos para vivir sometidos al arbitrio y voluntad de ninguno de sus semejantes, sino que Dios los crió libres para constituírse bajo la forma de gobierno que les parezca convenir mejor a su felicidad; no permitáis, Madre Amabilísima, que los pueblos de la 
Nueva Granada pierdan este derecho en manos de los injustos, crueles y obstinados españoles. Hacédles, Señora, sumisos constantemente a las leyes del cristianismo en el seno y bajo la autoridad de la Santa Iglesia Católica, Apostólica, Romana, y amantes de su libertad e independencia, al mismo tiempo que obedientes a las potestades que ellos mismos han constituído, y observantes de sus constituciones. Recibíd, inmaculada y poderosísima Reina del género humano, los cultos que os tributa el pueblo libre de la Nueva Granada en reconocida y tierna memoria de los dolores que padecísteis en el curso de vuestra santísima vida, y principalmente al pie de la Cruz, para que presentado las súplicas de tus fieles devotos, a tu Unigénito Hijo Jesucristo Nuestro Señor, nos alcancéis la gracia de vivir y morir incontrastables con tu protección bajo las banderas de tu imperio, libres en lo espiritual del poder de los enemigos de nuestras almas, y en lo temporal del yugo de los tiranos en la tierra". (Una novena, 1962). ("Una novena, cabeza de proceso", Boletín de Historia y Antigüedades, 49: 573-574 (1962): 363-366.)

En lo anterior se perciben las siguientes ideas: reconocimiento del único señorío de Dios y de la Virgen, creación en libertad de todos los hombres, autonomía para darse el gobierno que consideren conveniente (aquí se nota la influencia de Tomás de Aquino y Francisco Suárez) y rechazo a los tiranos de la tierra. El Dr. Plata advierte en la novena que hay que pedir a la Virgen que se compadezca de los pueblos oprimidos y los guíe en la defensa de sus derechos y los proteja en su libertad e independencia. (Tisnés, 1971, p. 533-534) "Cristo vive, Cristo impera, Cristo reina, Cristo defienda a la cristiana república de la Nueva Granada de la fuerza y dominio de los tiranos" (p. 486).

Por esta novena fue procesado el Dr. Plata, ya que se consideró como insurgencia, y es interesante conocer el concepto del Capellán Melgarejo sobre dicha novena:

"La dedicatoria de la Novena que se recuerda será siempre el mejor comprobante de los sentimientos revolucionariosy afección que ha profesado al gobierno ilegitimo en odio de la soberanía y que supo sagazmente difundirlos" (p. 535).

Por tanto, pide que sea llevado de estos dominios a España para ser encausado.

\section{La novena político-religiosa a una santa que no existió y que es patrona de la independencia}

"En la tarde del viernes 20 de julio, día de Santa Librada, parece que por un arcano misterioso de la Divina Providencia, estaba decretada la libertad de esta capital y de todo el Reino", así dice Manuel del Socorro Rodríguez (Rodríguez, 2007, p. 42) en su relato de lo sucedido el 20 de Julio de 1810, indicando que podría ser la patrona de la independencia. El 3 de enero de 1812, Antonio Narińo y el padre Francisco Antonio Florido presentaron la imagen de Santa Librada como símbolo de la libertad en una fiesta del Cabildo con su respectivo sermón. Sin embargo es sólo en 1813 que Antonio Nariño realiza la procesión de Santa Librada que continuó haciéndola hasta 1815. José María Caballero cuenta de las tres procesiones realizadas por él: 1813 a 1815. (Caballero, 1986, pp. 90-91; 137-140). Parece que como era ésta una devoción de la gente de los suburbios que apoyaba a Nariño, este aprovechó para fomentar esta celebración. (Almeida, 2009, 140). Narińo encontró así la llave simbólica adecuada para comenzar a ganarse al pueblo llano con la religiosidad popular y asegurarse el apoyo del clero. 
Del ańo de 1815 es la Novena a la Gloriosa Virgen y Mártir Santa Librada, Patrona, Protectora y Libertadora de los Ciudadanos de la Nueva Granada, redactada por Fray Miguel Antonio Escalante. 1815. Esta novena habla de la santa libertad, advierte a los idólatras infieles, y trae una rima en que el sacerdote decía: "Santa Librada tan liberal" y el pueblo respondía: "Oíd al pueblo en general" o "Sé nuestra libertadora en la vida y en la muerte". (Almeida, 2009, 144).

De 1816 en adelante se opacó la fiesta de la santa pero hay testimonios de su procesión en 1835 , 1836, 1837 (Almeida, 2014, p. 224), y en 1849 (González Pérez, 2009. P. 62, 64, 69), patrocinada por los liberales celebrando la manumisión de los esclavos con comidas, corridas de toros, chicha, música. Aparecen otras menciones de la procesión de Santa Librada en 1872, 1874,1886, 1890, 1891, 1910, 1929, 1938. (Almeida, 2009, 155-156) Hay registros fotográficos de 1872 que muestran a Murillo Toro, la Plaza de los Mártires, el arzobispo don Vicente Arbeláez, José María Rojas Garrido y la imagen del Cristo de los Mártires, pero ya en 1926, Arturo Quijano oficializa ese rito cívico-religioso en el proyecto de la Academia colombiana de historia, que colocaba a Francisco de Paula Santander como el padre fundador de la nación colombiana. (Almeida, 2014, 229). Almeida analiza así este renacimiento en época conservadora:

La tradición inventada por Antonio Narińo, de asociar ritualmente la memoria de la Independencia con la imagen de Santa Librada, hay que buscarla entre los liberales de corte santanderista y no en los barrios plebeyos y los círculos de artesanos, al menos desde los ańos 1835-1837. (Almeida, 2014, 229-230)

Lentamente fue decayendo esta fiesta, a pesar de que la Academia colombiana de historia trató de revivirla en el 2000 (Triana y Antorveza, 2000, p. 913-922). Las razones de este olvido, además de su supresión del santoral (En 1969, la Iglesia retiró la santa del Santoral católico por tratarse de una persona que no existió físicamente sino que se trataba de una leyenda piadosa originada en el siglo VIII), se deben a su relación con los plebeyos en época de Narińo cosa no bien vista por la élite, y su relación con los liberales en años posteriores. Parece que no era santa de devoción de los conservadores y sí de los liberales por su conexión con las clases sencillas de Bogotá. Luego la asumen los conservadores santanderistas, pero en 1951 comienza su decadencia definitiva hasta su desaparición en 1957. Hay que tener en cuenta que:

El Catolicismo, órgano oficial de la arquidiócesis, ni una sola vez mencionó los rituales patrióticos de Santa Librada. Tal vez porque, sobre el arzobispo don Vicente Arbeláez y sus asesores el doctor Joaquín Pardo Vergara y el canónigo Bernardo Herrera Restrepo, quienes reunieron a Santa Librada y el Cristo de los Mártires en los festejos de 1872, creando desde entonces un nuevo modelo para la conmemoración del 20 de julio, pesaba la sospecha de que serían masones. (Almeida, 2014, p. 234).

Después de la década del 60 del siglo XX, no se vuelve a celebrar la procesión y esta devoción cae en el olvido.

\section{Discusión}

La sociedad de la época de la independencia no era secular, por eso no diferenciaba la religión de la política. La intervención de Dios en la historia era concebida algo normal. Dios premiaba al pueblo si cumplía 
los mandamientos y lo castigaba si los olvidaba. Por eso se le suplicaba para que estuviese del lado de la propia ideología política. En la época de la independencia, la religión era el polo de referencia religioso, social y cultural con bastante poder de influencia. En un pueblo con unas creencias católicas tradicionales, aceptadas, normadas y con gran control social, la palabra de los clérigos era importante. La intervención de éstos tenía gran poder para guiar el comportamiento político de las personas. Por eso puede decir Arce (2012b, 103):

La persuasión se enfocaba en convencer al militante de que estaba en el bando avalado por el Ser Supremo y que si sufría una derrota a manos del enemigo, era porque así lo había establecido el mundo celestial. Con ello las batallas se consagraron como espacios bendecidos por el Dios de los ejércitos. Lo que a la postre significó un país sin rey, pero no sin Dios.

La decisión de irse por el lado republicano o el lado español se tomaba de acuerdo a las características sociales de los clérigos tales como origen racial, posición en la estructura eclesiástica, relaciones de parentesco y familia, influían en la opción por ser patriota o realista. Es el caso del obispo de Popayán Salvador Jiménez de Enciso que pasa de ser realista a independentista al ver el triunfo de Bolívar y reconocer que le sería más ventajoso permanecer como obispo de dicha ciudad (Pita, 2017, p. 50- 51; Hernández 1962, 418.) Así mismo, había quienes apoyaban a unos o a otros, según los vaivenes de la guerra: apoyar al que iba ganando era una posición común en algunos clérigos y comunidades religiosas. Como dice Pita:

Dada la intermitencia de los gobiernos, en ocasiones quedaban en evidencia los cambios o reacomodamientos repentinos de bando de acuerdo a los intereses personales o a las expectativas que ofrecía cada coyuntura. El pánico ante eventuales represalias o venganzas, el miedo ante la amenaza de perder privilegios ya alcanzados o el impulso natural de aventurarse a buscar mejores condiciones sociales y económicas fueron algunas de las justificaciones que pudieron explicar esas súbitas mutaciones en las lealtades políticas. (P. 50-51).

Un caso es el de los dominicos boyacenses que figuraron en las líneas patriotas pues "un cambio de régimen constituía una oportunidad para los frailes de ganar estatus y reconocimiento, al convertirse en figuras políticas regionales", mientras que los santafereños "pensaban que la independencia, según el modelo federalista, llevaría a la ciudad a la ruina y le quitaría su privilegiada condición de centro cultural y político. No extraña que la mayoría de los religiosos evitaran manifestarse públicamente, lo suficiente como para no ser sospechosos ante realistas y patriotas." (Plata, 2009, 301-302).

El clero patriota desarrolló una justificación teológica de la independencia opuesta a la justificación de la autoridad real como fundamentada en Dios. Aquí influye de manera importante la teoría de la soberanía del pueblo desarrollada en España. Pero además, la reflexión teórica se apoyaba en los íconos o símbolos religiosos que tienen un gran poder sobre el grupo. Así utilizar, poseer, manipular el símbolo era fundamental para mover los espíritus y las decisiones de las personas. Concientes de ello, tanto realistas como patriotas, supieron manejar los símbolos religiosos que, como tienen una sanción divina, son poderosos y eficaces. Tener la imagen, por ejemplo, es tener el apoyo de la divinidad; hacer la novena es asegurar la fuerza de Dios en su favor. La novena, por su parte, es un negocio entre el hombre y la divinidad: "yo hago la novena y Dios me hace el milagro", es un compromiso entre dos contratantes. 
Todo lo anterior supone la utilización de medios y estrategias de la mejor publicidad política para la época. La opinión pública era necesaria para inculcar significados políticos. (Ortega y Chaparro, 2012, p. 43). Es notar que la categoría de opinión pública no se entendía como se entiende hoy, apenas estaba en formación pues la vida social se articulaba fundamentalmente en torno a la iglesia y la Corte. Es sólo a partir de 1809 que se comienza a formar como percepción común a diversos actores de que se vivía un tiempo nuevo (p. 38, 40, 76). La meta era llegar a toda la comunidad con un mensaje didáctico, popular y sencillo con la ventaja de tener un fundamento divino, sacralizado por el prestigio de la estructura eclesiástica. Pero es todo un proyecto publicitario con el uso de símbolos, textos, didáctica y con amplia cobertura.

Todo el aparato simbólico, dogmático y popular se puso al servicio de una u otra manera de pensar mostrando una de las características de la evangelización católica: la acomodación a las circunstancias en una dialéctica de confrontación y aceptación con un pragmatismo político contextual.

\section{Conclusiones}

La religiosidad popular en su versión de novenas y de sermones tuvo una influencia grande en la lucha de independencia en cuanto buscaban el apoyo del pueblo para defender la causa patriota o la causa realista. Esto indica que la religión es un factor que influye en la política y tiene un papel legitimador de las posiciones sociales. Histórica y sociológicamente la religión no es una estructura independiente en la sociedad, sino una función interdependiente que no es ajena a la acción social. Ha sido defensora del status quo pero también ha tenido influencias en los cambios sociales, y esto hay que analizarlo y tenerlo en cuenta en su estudio.

Así se dio la misma relación durante todos los siglos XIX y XX colombianos donde se ve la imbricación de la religión con la política durante las guerras civiles y los gobiernos de esos tiempos en el conflicto entre tradición y modernidad.

Hoy se vuelve a tener en cuenta en los estudios políticos e históricos, la categoría religión. A principios y mediados del siglo XX, se fue abandonando el estudio de esta categoría por considerarse irrelevante en la sociedad, ya que era una realidad que iba a desaparecer bajo el impacto de la racionalidad. Los estudios políticos la ignoraron y los estudios históricos simplemente la miraron desde la óptica del materialismo dialéctico como alienación, superstición y engaño. Hoy, especialmente después de los sucesos de la aparición del fundamentalismo, el ingreso de la religión en la política, la participación política de ciertos grupos religiosos, la categoría religión vuelve a ser considerada en los estudios científicos de la sociedad. Los políticos se han dado cuenta de esta realidad y por eso buscan lograr el apoyo de los diversos grupos religiosos en una especie de utilización pragmática de los símbolos religiosos.

Desde un punto de vista funcionalista, la religión es una variable que puede ser independiente o dependiente según la coyuntura histórica de que se trate. Allí hay posibilidad de estudiar intereses de grupos o movimientos en esta funcionalidad o disfuncionalidad. El fundamentalismo, el integrismo y el giro a la derecha del momento actual, pueden tener una influencia grande en la conformación política de las naciones como se nota ahora en Europa, Brasil, o países orientales. 
Permanece la pregunta de si hay uso manipulativo de la religión por parte de la política o si el recurso a la religión es realmente existencial. Queda abierta la discusión en este campo pues el sentido de la existencia no siempre es el sentido que el uso político quiere lograr.

\section{Referencias}

\section{Archivos}

AGN (Archivo General de la Nación)

Serie Oratoria Sagrada. (1735 - 1850) Sermones patrióticos

BNC (Biblioteca Nacional de Colombia. Bogotá).

Fondos: Pineda, Quijano. Libros raros y curiosos

Fundación Antioqueña para los estudios sociales. FAES.

Se revisaron los textos novenarios.

\section{Fuentes primarias impresas}

Caballero, José María. (1986). Diario de la patria boba. Bogotá: Incunables.

Escalante, Miguel Antonio. (1815). Novena a la Gloriosa Virgen y Mártir Santa Librada, Patrona, Protectora y Libertadora de los Ciudadanos de la Nueva Granada, redactada por Fray Miguel Antonio Escalante, presbitero de la orden hospitalaria del Patriarca San Juan de Dios. Bogotá. Imprenta del C.B. Espinosa.

Sotomayor, Juan Fernández de. (1814). Catecismo de Instrucción Popular. Cartagena: Imprenta del gobierno de Don Manuel González y Pujol.

Novena en culto del glorioso Arcángel San Rafael compuesta por el presbítero Dr. Don Mariano de Mendoza Bueno y Fontal. Imprenta del gobierno por Nicomedes Lora. Año de 1816.

Novena en memoria y obsequio de los dolores de la Santísima Virgen María Nuestra Señora. Con la licencia necesaria. Santafé. Imprenta del Estado por el C. J. M. Ríos: Año de 1816.-6º.

Sermón que en la fiesta de Santa Librada hecha en obsequio del Exmo. Señor Presidente Don Antonio Nariño por el ilustre cabildo de la villa de Bogotá pronunció el Padre Franciscano Florido de la Orden de San Francisco, el día 3 de enero de 1812. Santa Fe de Bogotá. Imprenta de D. Bruno Espinosa. 1812

"Una novena, cabeza de proceso". Boletín de Historia y Antigüedades, 49: 573-574 (1962): 363-366.

\section{Fuentes secundarias}

Almeida, J. (2014). Santa Librada y la academia colombiana de historia. Boletín de historia y antigüedades. CI, 858, 219-242.

Almeida, J. (2009). ¿200 años de olvido? Santa Librada en la memoria de la independencia. En C. Acosta, C. Ayala, y H. Cruz (eds). Independencia, independencias y espacios culturales. Diálogos de historia y literatura.pp.139162. Bogotá: UNAL. 
Arboleda, Carlos. (2017). Estudios sobre la religión en Colombia (2000-2016). Un futuro plural para la religión en Colombia. Saarbrucken: Editorial académica española. https://www.researchgate.net/publication/318988724_ Estudios_sobre_la_religion_en_Colombia_2000-2016_Un_futuro_plural_para_la_religion_en_Colombia

Arce Escobar, V. (2012a). La biblia como fuente de reflexión política en los sermones neogranadinos1808-1821. Ciencias sociales (9), 273-308.

Arce Escobar, V. (2012b). El púlpito entre el temor y la esperanza: ideas de castigo divino y misericordia de Dios en la oratoria sagrada neogranadina, 1808-1820. Anuario de Historia Regional y de las Fronteras, 17 (1), 77 -107.

Caballero, J.M. (1902). Diario de la independencia. En: E. Posada y P. Ibáńez. La Patria Boba. Bogotá: Imprenta Nacional.

Cortés, J.D. (1996). Balance bibliográfico sobre la historia de la Iglesia en Colombia, 1945-1995. Historia Crítica, $12(20)$.

Cortés Guerrero, J. D. (2010a) La lealtad al monarca espańol en el discurso político religioso en el Nuevo Reino de Granada. Anuario colombiano de historia social y cultural, 37 (1), 43-83.

Cortés Guerrero, J. D. (2010b). Los sermones en la Independencia colombiana. De la defensa del monarca español a la defensa de la república, en B. Tovar Zambrano. Independencia. Historia diversa. Bogotá: Universidad Nacional de Colombia.

Garrido, M. (2004). Los sermones patrióticos y el nuevo orden en Colombia. 1819-1820. Boletín de Historia y Antigüedades, 91 (826), 461-484.

Garrido, Margarita. (2010). Palabras que nos cambiaron: lenguaje y poder en la independencia. Recuperado de http:// www.banrepcultural.org/palabras-que-nos-cambiaron/intro.html

González Pérez, Marcos. (2007). Fiesta y nación en Colombia. Bogotá: Cooperativa Editorial, Magisterio.

González, F. E. (2011). ¿ ¿Teología de la liberación en el siglo XIX?. Revista credencial, 248. Recuperado de http:// www.revistacredencial.com/credencial/historia/temas/teologia-de-la-liberacion-en-el-siglo-xix

GRCS. Grupo religión, cultura y sociedad. (2001). Historiografia sobre religión, cultura y sociedad en Colombia producida entre 1995 y el 2000. Medellín, Todográficas.

Groot, J. M. (1953). Historia eclesiástica y civil de Nueva Granada. Tomo III. Bogotá: Biblioteca de autores colombianos.

Hernández de Alba, G. (comp.), (1962). Sumarias de los procesos seguidos contra los clérigos patriotas. Boletín de Historia y Antigüedades, XLIX, 573-574: 345-436.

Marques Villamil, M.I. (1986). Monseñor Bernardo Herrera Restrepo en la vida politica colombiana. Bogotá: Universidad de la Sabana. Facultad de Comunicación Social y Periodismo.

Muradás García, F. (2016). La época de las independencias: Hispanoamérica 1806-1830. Guía de recursos bibliográficos en la Biblioteca Nacional de España. Madrid: BNE.

Ocampo López, J. (1997). Catecismos políticos en la independencia: un recurso de la enseńanza religiosa al servicio de la libertad. Revista Credencial, (85). Recuperado de http://www.banrepcultural.org/biblioteca-virtual/ credencial-historia/numero-85/catecismos-politicos-en-la-independencia

Ocampo López, J. Catecismos políticos en la independencia de Hispanoamérica. Tunja, UPTC.

Ocampo López, J. (1980). El proceso ideológico de la independencia de Colombia. Bogotá: Colcultura. 
Ocampo López, J. (2010). El Cura Juan Fernández de Sotomayor y Picón. Bogotá: Universidad del Rosario.

Ortega, F y Chaparro, A (ed). (2012). Disfraz y pluma de todos. Opinión pública y cultura política, siglos XVIII y XIX. Bogotá: UNAL y University of Helsinki.

Pita, R. (enero-junio, 2017). Clero y lealtades políticas en la independencia: el caso de Salvador Jiménez de Enciso, obispo de Popayán. Revista Investigium IRE: Ciencias Sociales y Humanas, 8 (1), 46-62

Plata, W.E. (2009). Un acercamiento a la participación del clero en la lucha por la independencia de Santafé y la Nueva Granada: el caso de los dominicos (1750-1815). Fronteras de la Historia 14 (2): 282-313.

Rodríguez, M. (2007). Relación sumaria instructiva de las novedades ocurridas en la muy noble y muy leal ciudad de Santafé de Bogotá, capital del Nuevo Reino de Granada, desde la tarde del 20 de julio de 1810, hasta el día de la fecha. En La Constitución Feliz. Periódico Politico y Económico de la Capital del Nuevo Reino de Granada, 1 (7 de agosto de 1810). Biblioteca Nacional de Colombia

Quintero, I. y Martínez, A. (ed). (2007). Actas de formación de juntas y declaraciones de independencia (1809-1822) Reales Audiencias de Quito, Caracas y Santa Fe. Tomo II. 41-62. Bucaramanga: UIS.

Romero, M. G. (1960). Novenas políticas en la Independencia. Boletín de Historia y antigüedades, 47 (549-551), 477-487.

Sáenz del Castillo, J. (in press). Politica y religión en los catecismos politicos americanos durante la independencia, 1786-1825. Recuperado de https://www.academia.edu/4589639/_IN_PRESS_Pol\%C3\%ADtica_y_religi\%C3\%B3n_ en_los_catecismos_pol\%C3\%ADticos_durante_la_independencia_de_Am\%C3\%A9rica_1786_1825

Sagredo Baeza, R (1996). Actores políticos en los catecismos patriotas y republicanos americanos 1810-1827. Historia Mexicana, 45 (3), 501-538.

Sagredo Baeza, R. (2009). De la colonia a la república. Los catecismos políticos americanos 1811-1827. Madrid: Fundación MAPFRE- Ediciones Doce Calles.

Suárez, F. (1970). Defensa de la fe. Madrid: Centro de estudios políticos y constitucionales.

Tisnés, R. (1971). Una novena patriótica. En Academia Colombiana de Historia. Historia extensa de Colombia. XIII. Tomo 4: 529-536. Bogotá: Lerner.

Tovar González, L. (2007). Catecismos políticos del siglo XIX. En Sierra Mejía, Rubén (ed). El radicalismo colombiano del siglo XIX. Bogotá: UNAL.

Triana y Antorveza, H. (2000). Oración a los Mártires de la Independencia. Boletín de Historia y Antigüedades de la Academia Colombiana de Historia, 87 (811), 913-922.

Vallecilla, N. (1990). Discursos, votos y novenas: subversión y reacción eclesiástica en el Nuevo Reino de Granada (1810-1816). Historia y espacio, (13), 111-120.

Victoria, F. (1960). Obras completas. Madrid, Biblioteca de Autores Cristianos. 